\title{
REFLEXÕES CRÍTICAS SOBRE A VIABILIDADE DE UM "CONSTITUCIONALISMO DO FUTURO" NO BRASIL: EXEGESE VALORATIVA ${ }^{1}$
}

\author{
CRITICAL REFLECTIONS ABOUT THE VIABILITY OF A \\ "CONSTITUTIONALISM OF THE FUTURE" IN BRAZIL: EXEGESIS OF VALUES
}

Rafael José Nadim de Lazari

\begin{abstract}
Resumo
Através dos métodos histórico, comparativo e dedutivo, este texto discorre sobre aquele que seria o sucessor do neoconstitucionalismo, a saber, o "constitucionalismo do futuro". Isto posto, em primeiro lugar, o estudo irá abranger as premissas básicas deste fenômeno, desenvolvido por José Roberto Dromi. Neste sentido, será visto se as características do "constitucionalismo do futuro" são, realmente, "do futuro", se já estão institucionalizadas na legislação em vigor - mas carentes de realização -, ou, se, simplesmente, representam as aspirações daquele que defende essas premissas. No final, tomando uma posição, dar-se-á parecer valorativo sobre o tema.
\end{abstract}

Palavras-chave: "Constitucionalismo do futuro". Neoconstitucionalismo. Normas constitucionais programáticas. Força normativa da Constituição Federal.

\begin{abstract}
Trough methods historical, comparative and deductive, this text discusses about that what would be the successor of neoconstitutionalism, ie, the "constitutionalism of the future." So, first, the study will cover the basic premises this phenomenon, developed by Jose Roberto Dromi. In this vein, will be seen if the characteristics of "constitutionalism of the future" are, really, "of the future", if are already institutionalized in the current legislation - but lacking in accomplishment -, or, if, merely, represents the aspirations of those who defends these premises. In the end, will be given a valorative opinion about the theme.
\end{abstract}

Keywords: "Constitutionalism in the future." Neoconstitutionalism. Constitutional programatic norms. Normative force of the Federal Constitution.

1 Artigo recebido em: 18/04/2011. Pareceres emitidos em: 10/06/2011 e 14/072010. Aceito para publicação em: 12/09/2011.

2 Advogado, consultor jurídico e parecerista. Mestrando-bolsista (CAPES/PROSUP Modalidade 1) em Direito pelo Centro Universitário "Eurípides" de Marília/SP - UNIVEM. Pesquisador do Grupo de Iniciação Científica "Novos Rumos do Processo de Conhecimento", sob orientação do Prof. Dr. Gelson Amaro de Souza. Colaborador permanente de diversos periódicos especializados de Direito. E-mail: rafa_scandurra@hotmail.com. 
Sumário: 1. Linhas prolegominais. 2. Breve síntese da evolução constitucionalist.; 3. Sobre as premissas do "constitucionalismo do futuro", por José Roberto Dromi; 4. Sobre a viabilidade de um "constitucionalismo do futuro" no Brasil: plausibilidade, repetitividade ou utopia?. 5. Linhas derradeiras; 6. Referências bibliográficas.

\section{LINHAS PROLEGOMINAIS}

Nunca o fenômeno constitucionalista ocidental esteve tão perto dos direitos e garantias fundamentais como nos tempos atuais. Tal movimento ganhou fôlego, sobretudo, a partir do pós-Segunda Grande Guerra, e, desde então, tem milagrosamente germinado em ambiente lúgubre, se observadas problemáticas como a Guerra Fria, os conflitos separatistas regionalizados, a invasão ocidental a países da "lua crescente", o populismo latino-americano, o combate ao Terror, dentre tantas outras adversidades.

Respostas a este paradoxo não faltam, mas é certo que são apenas suposições, com maior ou menor grau de fundamentação. No campo político, o advento do globalismo, do multiculturalismo, a adesão maciça aos blocos econômicos (sobretudo, o fortalecimento e a expansão da União Europeia), a criação de tribunais internacionais de julgamento de crimes de guerra e contra a humanidade, e as Nações Unidas, podem ser argumentos justificadores deste fenômeno binomial constitucionalismo/direitos e garantias fundamentais. No campo jurídico, a Lei Fundamental da Bonn ${ }^{3}$, a crise do positivismo ${ }^{4}$ e a volta de elementos

3 Promulgada aos 23 de maio de 1949, fundadora da República Federal da Alemanha, a Lei Fundamental de Bonn consistiu num paradigma inovador da própria noção de Estado Constitucional, conforme se pode extrair de suas características: "(i) a importância dada aos princípios e valores como componentes elementares dos sistemas jurídicos constitucionalizados, (ii) a ponderação como método de interpretação/aplicação dos princípios e de resolução dos conflitos entre valores e bens constitucionais, (iii) a compreensão da Constituição como norma que irradia efeitos por todo o ordenamento jurídico, condicionando toda a atividade jurídica e política dos poderes do Estado e até mesmo dos particulares em relações privadas, (iv) o protagonismo dos juízes em relação ao legislador na tarefa de interpretar a Constituição, e (v) a aceitação de alguma conexão entre Direito e Moral". (Discurso proferido em 25.5.2009 na Embaixada da República Federal da Alemanha, por ocasião dos 60 anos da Lei Fundamental de Bonn. s/n. In <http://www.stf.jus.br/arquivo/cms/noticiaArtigoDiscurso/anexo/discAlemanha.pdf>. Acesso em: 24 nov. 2010).

4 Lenio Luiz Streck (2009, p. 62) evidencia essa crise quando questiona o fato de se pensar um direito imune às influências metajurídicas em sua análise hermenêutica, como previa o positivismo em essência: "Nesse sentido há uma pergunta que se torna condição de possibilidade: por que o direito estaria "blindado" às influências dessa revolução paradigmática? Aliás, talvez por assim se pensar - e a dogmática jurídica e até mesmo algumas posturas que se pretendem críticas 
metajurídicos ao direito ${ }^{5}$, bem como o sentido jurídico atribuído às Constituições ${ }^{6}$, também podem ser consideradas algumas respostas.

Sem mais delongas, este artigo não almeja debruçar-se meramente sobre a evolução do constitucionalismo, até porque isso não é trabalho para as poucas páginas de um artigo científico. Ateremo-nos apenas a pontos nevrálgicos, meramente exemplificativos, de cada etapa evolucionista, que serão importantes quando o trabalho desembocar em seu eixo central, que é o "constitucionalismo do futuro" (ou "constitucionalismo por vir"), e as sete premissas desenvolvidas por José Roberto Dromi ${ }^{7}$. Desculpamo-nos, então, de antemão, por eventual omissão desagradável aos olhos e à opinião do leitor.

Isto posto, insta saber de que forma pode-se enxergar o futuro do constitucionalismo, no intento de corrigir os excessos e devaneios neoconstitucionais ${ }^{8}$, sem, contudo, repetir os percalços criados pelo positivismo extremado à implementação de direitos fundamentais.

Mas isso já é assunto para outro capítulo.

apostam na presença da filosofia do direito tão somente como "capa de sentido" - é que o direito continua até hoje refém, de um lado, do objetivismo e, de outro, do solipsismo próprio da filosofia da consciência. Ou seria possível conceber o direito isolado das transformações ocorridas na filosofia (da linguagem)?". (grifei)

5 Vide nota explicativa $n^{\circ} 1$.

6 Cf. Luís Roberto Barroso (2000, p. 68), em análise ao ideário de Konrad Hesse: "Na vertente liberal, Konrad Hesse, em lição primorosa, assinala que a Constituição jurídica vem condicionada pela realidade histórica. Mas ela não é apenas a expressão da realidade de cada momento. Graças ao seu caráter normativo, ordena e conforma à sua vez a realidade social e política. Dessa coordenação correlativa entre o ser e o dever ser derivam as possibilidades e, ao mesmo tempo, os limites da força normativa de uma Constituição. E essa força normativa não se baseia apenas em adaptação inteligente às circunstâncias: a Constituição jurídica tem uma significação autônoma, ainda que apenas relativa".

7 José Roberto Dromi (1997).

8 Cf. Daniel Sarmento (2009, p. 52-53), que levanta três acertadas críticas ao neoconstitucionalismo: "a) a de que seu pendor justicialista é anti-democrático; b) a de que a sua preferência por princípios e ponderação, em detrimento de regras e subsunção, é perigosa, sobretudo no Brasil, em razão de singularidades da nossa cultura; e c) a de que ele pode gerar uma panconstitucionalização do Direito, em detrimento da autonomia pública do cidadão e da autonomia privada do indivíduo". 


\section{BREVE SÍNTESE DA EVOLUÇÃO CONSTITUCIONALISTA}

Como força reativa equivalente aos movimentos absolutistas do período medieval, e como embrionário da concretização futura dos Estados Nacionais, o constitucionalismo surgiu em oposição ao caráter divino e/ou imperativo do monarca, num tentame de impor limitação ao poder e seus desdobramentos negativos, como o autoritarismo e a censura ${ }^{9}$. Com efeito, em que pesem as diversas fases pela qual o constitucionalismo passou ${ }^{10}$, sempre Ihes foram características comuns, em maior ou menor grau de intensidade, a limitação ao governo dos homens, a separação de funções e a garantia de direitos ${ }^{11}$.

Sendo assim, de início, como primeira fase tem-se o constitucionalismo antigo, identificado por Karl Loewenstein ${ }^{12}$ entre os hebreus e nas Cidades-Estado gregas.

Mas, na forma mais robusta e nos moldes primários do que se vive hoje, o constitucionalismo somente ganhou força na Idade Média, com a Magna Carta de 1215, com a Petition of Rights, de 1628, o Habeas Corpus Act, de 1679, e o Bill of Rights, de 1689. A importância do período consiste nas primeiras Cartas escritas e nos primeiros resquícios de proteção de direitos individuais.

9 Neste sentido, oportunas as palavras de André Ramos Tavares (2003, p. 13): Em todas as suas fases sucessivas, o constitucionalismo apresentou um traço constante, desde o início, que é a limitação do governo pelo Direito, as denominadas "limitações constitucionais". Essa é a nota mais antiga e, ao mesmo tempo, a mais recente, no constitucionalismo. Opõe-se, desde sua origem, ao governo arbitrário. (grifei).

10 Joaquim José Gomes Canotilho (1999, p. 47) defende um constitucionalismo uno, mas com vários "movimentos constitucionais" em seu conteúdo: "Será preferível dizer que existem diversos movimentos constitucionais com corações nacionais mas também com alguns elementos de aproximação entre si, fornecendo uma complexa tessitura histórico-cultural. E dizemos ser mais rigoroso falar de vários movimentos constitucionais do que de vários constitucionalismos porque isso permite recortar desde já uma noção básica de constitucionalismo".

11 Neste sentido, as palavras de Gerardo Pisarello (2007, p. 159), que demonstram a preocupação do constitucionalismo com estas questões: "En ese marco, ha supuesto también un desafio central al paradigma constitucionl entendido como sistema de vínculos y controles a los poderes públicos e privados en beneficio de los derechos de las personas". (grifei). Em mesma sintonia, Mário Lúcio Quintão Soares (2006, p. 48): "Ambos, o Estado e o constitucionalismo, lastreiam-se na garantia dos direitos fundamentais e na separação de poderes, compreendidos como identidade e rosto do Estado democrático de direito".

12 Karl Loewenstein (1970).

Constituição, Economia e Desenvolvimento: Revista da Academia Brasileira de Direito Constitucional.

Curitiba, 2010, vol. 2, n. 3, Ago-Dez. p. 341-357. 
Posteriormente, tem-se o constitucionalismo clássico (ou liberal), que se inicia com a Constituição dos Estados Unidos da América, em 1787, e com a Constituição Francesa, de 1791, que durou apenas dois anos, e que teve como preâmbulo a Declaração Universal dos Direitos do Homem e do Cidadão, de 1789. Neste período, inaugura-se a característica da rigidez constitucional, e é justamente nesta etapa de constitucionalismo rígido que surge a ideia de supremacia formal da Constituição, o que desencadeia, por consequência, o Controle de Constitucionalidade, surgido em 1803, pela via difusa, no famoso caso Marbury vs. Marshall. Além disso, juntamente com a já propalada ideia de supremacia constitucional, vem a atribuição ao Poder Judiciário de assegurá-la. Por fim, é dentro do constitucionalismo liberal que surge a primeira dimensão de direitos fundamentais (valor liberdade), feita, no Brasil, por Paulo Bonavides.

No período pós-Primeira Grande Guerra, inicia-se a etapa mais curta porém, não sem menor importância - do movimento constitucionalista, a saber, o constitucionalismo moderno (ou social). Com efeito, o liberalismo burguês cômodo, não intervencionista e exclusivista se revelou improfícuo em face das demandas sociais do período, o que levou à bancarrota o Estado Gendarme e o constitucionalismo liberal, clarificando-se a necessidade de uma onipresença estatal na vida cotidiana. Vale lembrar que a Europa estava devastada por um primeiro conflito de caráter mundial, havia feridas não cicatrizadas materializadas pela "paz aparente" do Tratado de Versalhes, e o socialismo "soprava do vento leste". É neste período que surge o positivismo jurídico, em substituição ao jusnaturalismo do período anterior, separando direito e moral. Ademais, é durante o constitucionalismo social que surge a segunda dimensão de direitos fundamentais, predominantemente individual, ligada à igualdade, bem como as chamadas "garantias institucionais"13.

Mas, como dito alhures, o constitucionalismo moderno pouco durou, pois, entre o final da década de 1930 e o primeiro lustro dos anos 1940, a ascensão das "ditaduras democráticas" nazifascistas mergulhou o mundo em outra Grande Guerra. Ao seu fim, surge o constitucionalismo contemporâneo (ou "neoconstitucionalismo") (ou, ainda, "pós-positivismo), que perdura até hoje. É aqui que o discurso começa a

13 Clarividente, neste período, a influência das Constituições Mexicana, de 1917, e da República de Weimar, de 1919, bem como a ameaça da bem-sucedida Revolução Bolchevique, de 1919, o que fez com que direitos sociais passassem a ser previstos nos Textos Constitucionais ocidentais muito mais por temor à "Cortina de Ferro", que por benevolência propriamente dita. 
ser no sentido de superar a dicotomia entre direito natural e direito positivo, equacionando os valores "justiça" e "segurança jurídica". É nesta fase, também, que surge a terceira dimensão de direitos fundamentais, ligada à fraternidade (predominantemente coletiva), e o Estado Democrático de Direito.

Acerca do "neoconstitucionalismo", ainda, há imperiosa consideração a ser feita, e que muita influenciará nas argumentações do trabalho em elaboração, qual seja, a ideia de normatividade da Constituição, cujo maior expoente é Konrad Hesse. Melhor explicando, através da "normatividade", subtrai-se o viés preeminentemente político de um Texto Supremo, para atribuir-lhe sentido jurídico (vide nota explicativa $n^{\circ} 4$ ), confirmando a tendência iniciada já no constitucionalismo clássico. Com isso, solidifica-se a ideia de superioridade constitucional e os desdobramentos deste fenômeno, como a filtragem constitucional, a ideia de constitucionalização do direito, a eficácia horizontal dos direitos fundamentais, e o fortalecimento do Poder Judiciário (hoje, chega-se a falar na "judicialização da política", inclusive).

E, existe alguma coisa depois do constitucionalismo contemporâneo? Isso será melhor visto no próximo tópico.

\section{SOBRE AS PREMISSAS DO "CONSTITUCIONALISMO DO FUTURO”, POR JOSÉ ROBERTO DROMI}

Em linhas primeiras, o "constitucionalismo do futuro" consiste numa projeção do que haveria depois do neoconstitucionalismo, em analisando as mudanças dessa etapa atual, as críticas que lhe vêm sendo feitas, e o sobrepujamento evolucionista natural do fenômeno constitucionalista. Também chamado de "constitucionalismo vindouro", ou de "constitucionalismo por vir", sobre o tema destacam-se as ideias de José Roberto Dromi, jurista argentino, que prevê um equilíbrio entre os atributos do constitucionalismo moderno e os excessos do constitucionalismo contemporâneo.

Para o autor, as Constituições do futuro teriam sete valores fundamentais supremos: verdade, solidariedade, consenso, continuidade, participação da sociedade na política, integração, universalização dos direitos fundamentais para todos os povos do mundo ${ }^{14}$.

14 Pedro Lenza (2009, p. 07-08) traz uma breve síntese explicativa destas premissas: "O constitucionalismo do futuro sem dúvida terá de consolidar os chamados direitos humanos de 
Melhor discorramos sobre cada um deles, dissecando o entendimento de Dromi.

Por verdade, entende-se a preocupação com a necessidade de promessas factíveis pelo Constituinte. De nada adiantaria uma Carta dotada de excessivo protecionismo, mas destituída de qualquer exequibilidade. Seria o desvencilhamento, do Texto Constitucional, de tudo aquilo que pode constituir mera carta de intenções, elaborada sem qualquer fundamento ou cientificidade. Em outras palavras, seria o equivalente a dizer que "cada Estado tem a Constituição que pode ter", isto é, respeitadas regras mínimas e suficientes de previsão de direitos fundamentais, em todas as suas subespécies (direitos individuais, direitos sociais, direitos políticos etc.), ficaria o constituinte impedido de enganar seu povo ${ }^{15}$.

Ademais, denota-se, já nesta primeira característica, um claro acoplamento entre os constitucionalismos moderno e contemporâneo, ao passo que

terceira dimensão, incorporando à ideia de constitucionalismo social os valores do constitucionalismo fraternal e de solidariedade, avançando e estabelecendo um equilíbrio entre $o$ constitucionalismo moderno e alguns excessos do contemporâneo [...]. Trata-se da constituição do "por vir", com os seguintes valores: verdade: a constituição não pode mais gerar falsas expectativas. O constituinte só poderá "prometer" o que for viável de cumprir, devendo ser transparente e ético; solidariedade: trata-se de nova perspectiva de igualdade, sedimentada na solidariedade dos povos, na dignidade da pessoa humana e na justiça social; consenso: a constituição do futuro deverá ser fruto de consenso democrático; continuidade: ao se reformar a constituição, a ruptura não pode deixar de levar em conta os avanços já conquistados; participação: refere-se à efetiva participação dos "corpos intermediários da sociedade", consagrando-se a ideia de democracia participativa e de Estado de Direito Democrático; integração: trata-se de previsão de órgãos supranacionais para a implementação de uma integração espiritual, moral, ética e institucional entre os povos; universalização: refere-se à consagração dos direitos fundamentais internacionais nas constituições futuras, fazendo prevalecer o princípio da dignidade da pessoa humana de maneira universal e afastando, assim, qualquer forma de desumanização".

15 André Ramos Tavares (2003, p. 14) tece posicionamento diferente, complementar, acerca da verdade: "Importa salientar, aqui, o constitucionalismo da verdade. Nesta referência existem duas categorias de normas a serem analisadas. "Uma parcela, que é constituída de normas que jamais possam ser programáticas e são praticamente inalcançáveis pela maioria dos Estados; e outra sorte de normas que não são implementadas por simples falta de motivação política dos administradores e governantes responsáveis". "As primeiras precisam ser erradicadas dos corpos constitucionais, podendo figurar, no máximo, apenas como objetivos a serem alcançados a longo prazo, e não como declarações de realidade utópicas, como se bastasse a mera declaração jurídica para transformar-se o ferro em ouro. As segundas precisam ser cobradas do Poder Público com mais força, o que envolve, em muitos casos, a participação da sociedade na gestão das verbas públicas e a atuação de organismos de controle e cobrança, como o Ministério Público, na preservação da ordem jurídica e consecução do interesse público vertido nas cláusulas constitucionais". 
institucionaliza a Reserva do Possível como elementar mitigadora da aplicação de preceitos magnos ${ }^{16}$, mas salvaguarda o mínimo existencial ${ }^{17}$.

Já por solidariedade, entendemos que deste valor elencado por Dromi extraise um triplo significado: primeiro, o de solidariedade entre os povos; segundo, o de necessidade de implementação expressa desta dimensão fraternitária de direitos fundamentais nas Constituições ocidente afora, algo que poucos Textos fazem explicitamente. A Constituição Federal pátria, p. ex., em momento algum consagra um Princípio da Solidariedade de maneira expressa, a exemplo do que faz com a Igualdade e a Liberdade, içadas à categoria fundamental de direitos ${ }^{18}$.

Noutro enfoque, o terceiro, a solidariedade pode ser vista como um clamor aos tempos de cooperação e tolerância, bem como de redução de desigualdades étnicas, religiosas, raciais, etc., almejando o agrupamento, independentemente de qualquer ideologia, sob uma mesma batuta, que é uma Constituição. As Constituições deixariam de ser um mecanismo equacionador de igualdade entre diferentes filosofias e preocupado excessivamente com as minorias, como acontece hoje.

O consenso, por sua vez, grande relação guarda com a solidariedade. Com efeito, sabe-se que gente das mais diferentes matizes políticas se une para elaborar

16 Em sentido contrário, Andreas J. Krell (2002, p. 52-54): "Segundo o Tribunal Constitucional Federal da Alemanha, esses direitos a prestações positivas (Teilhaberechte) "estão sujeitos à reserva do possível no sentido daquilo que o indivíduo, de maneira racional, pode esperar da sociedade". Essa teoria impossibilita exigências acima de um certo limite básico social; a Corte recusou a tese de que o Estado seria obrigado a criar a quantidade suficiente de vagas nas universidades públicas para atender a todos os candidatos [...]. Pensando bem, o condicionamento da realização de direitos econômicos, sociais e culturais à existência de "caixas cheios" do Estado significa reduzir a sua eficácia a zero; a subordinação aos condicionantes econômicos relativiza sua universalidade, condenando-os a serem considerados "direitos de segunda categoria". Num país com um dos piores quadros de distribuição de renda do mundo, o conceito da "redistribuição" (Umverteilung) de recursos ganha uma dimensão completamente diferente".

17 Acerca do "mínimo", oportunas as palavras de Ana Carolina Lopes Olsen (2008, p. 318): "Todavia, ainda que a definição de um mínimo existencial possa variar, é possível reconhecer que determinadas prestações materiais incumbidas ao Estado pelo constituinte são essenciais para a manutenção da vida humana com dignidade. Sempre que a vida humana, e a personificação do homem (em contraposição à ideia de coisificação do homem) estiverem em risco, poderá o intérprete aquilatar a presença do mínimo existencial (Ana Carolina, fls. 318).

18 A única previsão de solidariedade na Constituição Federal está no art. $3^{\circ}$, I: "Art. $3^{\circ}$ Constituem objetivos fundamentais de República Federativa do Brasil: I - construir uma sociedade livre, justa e solidária". (grifei). 
leis, decretos, e, principalmente, Constituições. Neste prumo, em pensando numa decisão incondicional, com absoluta aprovação, aqui o consenso se faz desnecessário. A maioria já basta.

Agora, como acontece na maior parte das vezes, a diversidade de argumentos e ideologias faz com que se impossibilite uma decisão unânime. Isso é uma consequência natural do pluralismo político. É aqui que entra em cena o consenso, consubstanciado na capacidade de fazer valer aquilo que um grupo, não necessariamente uma maioria, decidiu, sem que haja rupturas neste processo decisório. Disso infere-se, pois, que o consenso não significa maioria, como erroneamente se possa pensar. Pelo contrário, pressupõe a manutenção da iquebrantabilidade da ordem democrática, com a adesão solidária da parte que consentiu, consensualmente, em prol de um interesse maior.

Dando prosseguimento, a continuidade deve ser analisada sob dos dois ângulos distintos: o primeiro consiste na necessidade de uma Constituição respeitar a história de um país. As Constituições podem ser consideradas os "Estatutos Vigentes" de uma Nação, mas não implicam, necessariamente, no surgimento desta, salvo se na condição de Constituições históricas. Ora, é óbvio que uma Carta é capaz de definir diretrizes múltiplas para o povo que tutela, mas em momento algum deve desrespeitar a história do país e das pessoas que por sua unidade e prosperidade lutaram. Isso representa a continuidade do ciclo evolutivo de um país. Já num segundo enfoque, continuidade pode ser entendida como a escala desenvolvimentista de um povo. Deve-se visar, sempre, ao desenvolvimento de direitos, partindo não de uma "folha em branco", mas dos direitos já consagrados hoje, buscando sempre melhorá-los, nunca piorá-los.

Em suma, pois, deve-se privilegiar a continuidade, vez que qualquer ruptura profunda a um ordenamento, ou a excessiva alteração a uma Constituição, pode constituir ato pernicioso, violador desta característica ${ }^{19}$.

A participação refere-se à necessidade de influência da sociedade na política, o que representa um avanço no processo democrático, ao passo que

19 Cf. José Roberto Dromi apud André Ramos Tavares (2003, p. 14): “[...] é muito perigoso em nosso tempo conceber Constituições que produzam uma ruptura da lógica dos antecedentes, uma descontinuidade com todo o sistema precedente". 

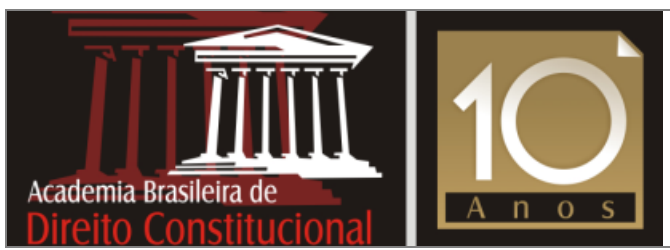

Reflexões Críticas sobre a viabilidade...

transpassa a mera condição de alistável do cidadão, para incluí-lo como voz a ser ouvida na tomada de direções. Em outras palavras, mais que o direito de voto, o cidadão passa a ter direito de voz.

De outra forma, esta participação também pode ser encarada como o controle dos atos, típicos e atípicos, praticados pelos integrantes das três esferas de funções, bem como a verificação do atendimento dos princípios inerentes à Administração Pública.

A penúltima característica, integração, consiste na comunhão entre os povos, por meio de políticas e órgãos transnacionais. Valendo-se do encurtamento de distâncias provocado pelo desenvolvimento das telecomunicações e dos meios de transporte, bem como do respeito para com o estrangeiro em prol da reciprocidade, tal característica representa o rompimento dos feudos a que se resumiram alguns povos nos últimos tempos, para disponibilizá-los outros pontos de vista, desde que respeitada sua identidade e cultura embrionária.

Por fim, a última característica é a universalização dos direitos fundamentais para todos os povos do mundo. Seria a busca de uma "fórmula mágica fundamental", com a dignidade da pessoa humana como denominador comum, que pudesse ser aplicada em qualquer parte do mundo, da desenvolvida Alemanha, $p$. ex., aos ditos países subdesenvolvidos.

\section{SOBRE A VIABILIDADE DE UM “CONSTITUCIONALISMO DO FUTURO” NO BRASIL: PLAUSIBILIDADE, REPETITIVIDADE OU UTOPIA?}

Postas, no tópico anterior, as sete características fundamentais do "constitucionalismo do futuro" de Dromi, convêm responder às indagações feitas no capítulo em desenvolvimento: é plausível um "constitucionalismo vindouro"? É utópico? Ou é uma mera repetição conglobada de institutos outrora já desenvolvidos nas outras etapas constitucionalistas?

Com efeito, consignando, desde já, o respeito a opiniões divergentes, merece acolhida entendimento pelo qual não existe um "constitucionalismo do futuro". Não nos moldes propostos por seu criador, ao menos. Tratam-se de 
proposições que, ou refletem o ânimo de quem as escreve, ou já estão institucionalizadas por meio de mecanismos símiles, ou são, simplesmente, incríveis.

Discorramos sobre cada uma delas, agora com visão crítica.

Acerca da verdade, é fato que mostra-se como medida salutar a não assunção, pelo constituinte, de compromissos desprovidos de concretude. $O$ problema é que, no Brasil, superado um primeiro momento de euforia de reabertura política e de democracia plena, em que uma ideia de welfare-state ecoou incondicionadamente pela doutrina constitucional, pode-se dizer que as funções estatais colocaram um "pé no freio" quanto à possibilidade de atingimento irrestrito de pessoas.

Ora, é farta a jurisprudência brasileira atestando a incapacidade do Estado em atender a todas às necessidades constitucionalmente previstas. Basta ver as questões envolvendo internações hospitalares à base de comando judicial, o abarrotamento do sistema prisional e a consequente soltura de presos por essa razão, o fornecimento de medicamentos e a busca de critérios pelo STF mediante a utilização de audiências públicas etc. Afinal, o que mais é isso que não o compromisso com a verdade? A atestação de incapacidade estatal em atender e solucionar as mazelas sociais é a demonstração da verdade, nua e crua, de que o Estado não é onipresente o bastante como um dia pensou o bem-estar social.

Noutra esfera argumentativa, sabe-se que há normas constitucionais sociais carecendo de regulamentação infraconstitucional, e, dentre estas, estão aquelas de princípio programático, consistentes em regras e princípios que preveem a implementação de diretrizes e programas de governo e que, desde que perderam sua conotação política que quase as levou à "falência", vem-se pacificando o entendimento, no Supremo Tribunal Federal, de que as tais normas não podem se transformar numa promessa inconsequente dos Poderes Públicos fraudando a expectativa do povo. Essa é outra demonstração de compromisso com a verdade, que não precisa ocorrer somente "no futuro".

No que atine à solidariedade e à integração entre os povos, tais características talvez pudessem melhor servir como norte para espaços ideologicamente delimitados pelo ódio entre extremistas e conservadores, xiitas e sunitas, israelenses e palestinos, indianos e paquistaneses etc. O Brasil é formado 
por uma identidade miscigenada, não-perfeita, é verdade, mas longe de ser um problema em nível de beligerância ou de guerra civil interna ${ }^{20}$.

Sobre a integração, aliás, insta frisar que já adota-se uma política diplomática do diálogo, que permite à Nação negociar, ao mesmo tempo, com o Irã e os EUA, p. ex. Sem contar o relacionamento pacífico com os vizinhos do sul, dos Andes e do Caribe, bem como a posição de destaque e liderança no Mercosul.

Além desta questão política integradora favorável, existem outros instrumentos que podem ser extraídos do Princípio da Solidariedade, ainda que não esteja o mesmo expressamente disposto na Constituição Federal, como é o caso das ações afirmativas, do mecanismo securitário social de arrecadação de muitos para custeio de alguns, da distribuição de competências tributárias e de tributos etc.

Tais dados somente confirmam que a solidariedade, num país como o Brasil, jamais poderia ser dispensada, obviamente, mas que não constitui extrema urgência sua previsão no ordenamento pátrio como necessidade de diminuir discrepâncias.

No pertinente ao consenso, sabe-se que há muito as Constituições ocidente afora deixaram de ser sinônimo de maioria. Isso se deu, inclusive, com a transição do viés político para um enfoque jurídico das Constituições pós-Segunda Grande Guerra (vide, mais uma vez, nota explicativa $n^{\circ} 4$ ). Até porque, do contrário, se estaria legitimando a perpetuação da maioria no poder, o esmagamento das minorias, e o impedimento de ascensão destas últimas a um nível maior de influência na tomada de decisões político-administrativas pátrias. Isto posto, fato é que, com a supramencionada transição, as Constituições tornaram-se o mecanismo de manutenção destas minorias e de controle das maiorias. Em termos práticos, atualmente, uma Constituição pode representar tanto uma vontade da maioria, como uma vontade da minoria, assim como pode vetar tanto maioria como minoria.

Neste diapasão, se foi dito que o consenso de Dromi representa o respeito a uma decisão não necessariamente majoritária, como forma de assegurar a iquebrantabilidade da ordem constitucional, significa que as Constituições atuais

20 Ademais, a Constituição Federal, em seu art. 4º prevê o seguinte: "Art. $4^{\circ}$ A República Federativa do Brasil rege-se nas duas relações internacionais pelos seguintes princípios: [...] IX - cooperação entre os povos para o progresso da humanidade". Isso é mais um elemento que confirma que a solidariedade, no Brasil, não é uma premissa "do futuro". 

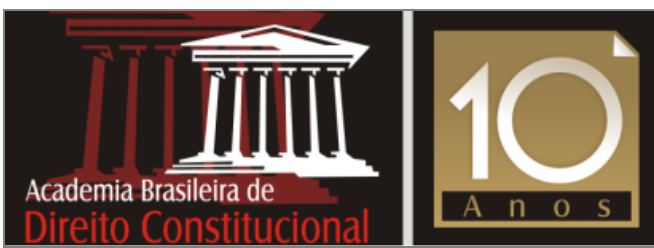

Rafael José Nadim de Lazari

tornaram-se sinônimo de consenso. Logo, desnecessário falar em consenso como uma premissa "do futuro", se este pressuposto está em plena aplicabilidade hodierna.

No que tange à continuidade, partida em dois enfoques no capítulo anterior, reconhece este autor haver falha em uma de suas facetas, que não recomenda alterações excessivas numa Constituição como forma de garantir sua concretização e um estado de tranquilidade aos por elas tutelados, no Brasil. Infelizmente, esse é um "costume maldito" que persiste, apesar da rigidez constitucional e do quórum específico para Emenda. Não que algumas não fossem necessárias, mas quanto a outras alterações, seria preciso uma discussão mais aprofundada de sua introdução na Magna Carta pátria, vez que, ao diluir-se, a conta-gotas, o Poder Constituinte Originário, vai-se retirando, também, a identidade atribuída por uma Constituição a um país. Não que se defenda o interpretativismo originalista ${ }^{21}$, mas algo temos a aprender com a experiência, bem-sucedida e única, norte-americana, de 1787.

No mais, ainda falando em continuidade, há que se defender, por outro lado, que seu enfoque que denota a necessidade de ampliação contínua de direitos e garantias fundamentais, sobretudo os sociais, com um mínimo possível de involuções e retardos, também já encontra implementada no constitucionalismo atual, na forma da Proibição do Retrocesso ${ }^{22}$.

Dando prosseguimento, no tocante à participação da sociedade na vida política, obtempera-se que o Brasil já dispõe de inúmeros mecanismos efetivadores de tal pressuposto, como é o caso do assento eclético no Conselho Nacional de Justiça, pós EC no 45/200423, de instrumentos de vontade popular, como plebiscito,

21 Cf. Elival da Silva Ramos (2010, p. 130), por interpretativismo originalista deve-se entender a teoria de interpretação constitucional que toma o texto da Constituição tão autoritariamente como o textualismo. A diferença é que olham os originalistas, para além de uma linguagem textual, para o significado que os constituintes ou as ratificações pretenderam dar ao texto.

22 Cristina M. M. Queiróz (2002, p. 151), em análise à obra de J. J. Gomes Canotilho, afirma: "Os direitos econômicos, sociais e culturais, garantidos por normas de escalão constitucional, dispõem de vinculatividade normativa geral [...]. Implicam, genericamente, segundo Gomes Canotilho: [...] c) e, por último, a proibição do retrocesso social, querendo com isso significar que, uma vez consagradas legalmente as "prestações sociais" (v. g., de assistência social), o legislador não pode depois eliminá-las sem alternativas ou compensações".

23 Art. 103-B. O Conselho Nacional de Justiça compõe-se de 15 (quinze) membros com mandado de 2 (dois) anos, admitida 1 (uma) recondução, sendo: [...] XIII - dois cidadãos, de notável saber jurídico e reputação ilibada, indicados um pela Câmara dos Deputados e outro pelo Senado Federal". 
o referendo e a iniciativa popular (art. 14, I, II e III, CF), além, é claro, dos writs constitucionais, como o Mandado de Segurança (art. 5, LXIX, CF), o Mandado de Injunção (art. 5, LXXI), o Habeas Data (Art. 5, LXXII), e a Ação Popular (art. 5, LXXIII).

Por fim, como última premissa elencada por Dromi, constitutiva do "constitucionalismo do futuro", situa-se a universalização dos direitos fundamentais para todos os povos do mundo. Aqui reside, na opinião deste autor, o elemento de maior discordância como um pressuposto "do futuro".

Com efeito, ao longo desta obra, o leitor mais atento certamente deve ter percebido que se utilizou a expressão "Constituições ocidente afora", e não "Constituições mundo afora", dividindo, temerariamente, o mundo em apenas duas partes, por um mero meridiano, e resguardando as características do constitucionalismo exclusivamente ao oeste.

Isto porque este autor, - como a primeira premissa de Dromi -, tem um compromisso com a verdade, e não pode deixar-se enganar sobre a pérfida possibilidade de uma homogeneidade constitucional entre oriente e ocidente. Os argumentos são múltiplos, da natureza legal à consuetudinária, da regra ao axioma, dentre os quais se pode, resumidamente, afirmar que toda a concepção evolutiva do constitucionalismo que se estuda atualmente é feita com base em institutos de países que compõem o bloco ocidental, como é o caso dos EUA, da Alemanha, da Inglaterra e da França. Ademais, ao se estudar os sistemas jurídicos, muito se fala do common law anglo-saxão e do civil law franco-romano-germânico, mas pouco ou nada se fala do direito soviético, do direito chinês e do direito árabe, $p$. ex.

Longe, aqui, querer criticar estes sistemas, até porque, vale reafirmar, pouco se sabe sobre eles. E por pouco deles se saber é que seria extremamente pretensioso estender para o "lado de lá" os nossos direitos fundamentais, em prol de uma pretensa e tendenciosa universalização. Até porque a hipocrisia não pode ser esquecida: ao exportar nossos ditos direitos fundamentais, isso seria chamado "universalização"; ao importar os direitos deles ditos fundamentais, isso seria considerado uma afronta ao marco civilizatório e democrático alcançado pelo ocidente. 
Ora, é ululante a impossibilidade de se conviver com uma Constituição mundial dotada de completude de essência, tão menos com uma gama estendida de direitos fundamentais. Uma Constituição mundial seria mera proposição teórica, desprovida de aplicabilidade, ou é de se acreditar que a Coréia do Norte respeitaria o direito à liberdade de expressão? Que a China deixaria de ser uma grande poluidora?

Por outro lado, partindo de "lá" pra "cá", será que aceitaríamos as extenuantes jornadas de trabalho chinesas como compatíveis com os Direitos Sociais aqui solidificados? E a poligamia árabe? E as ampliadas hipóteses de pena de morte? $\mathrm{E}$ a inferiorização da mulher, renegada à condição de objeto? O que faríamos com o Princípio da Igualdade?

Disso infere-se que esta sétima premissa do "constitucionalismo vindouro" estaria ferindo a primeira, a saber, a verdade, já que, mais uma vez, e como de costume, o "constituinte mundial" estaria tentando consubstanciar uma proposição ilógica e desprovida de concretude ${ }^{24}$.

Enfim, por estas razões acima aduzidas, conclui-se não haver um "constitucionalismo por vir" viável ao modelo constitucional brasileiro, nos moldes propostos por Dromi. Ou se tratam de premissas já vigentes, ou simplesmente inaplicáveis, ou meras aspirações de quem as desenvolve.

Por todo o explanado, em apertada síntese conclusiva, as conclusões que se extraem são as seguintes:

24 Vejamos o problema de um constitucionalismo universal. André Ramos Tavares (2003, p. 15) afirma que: "Nessa reconhecida busca por maior integração insere-se uma tentativa de ampliação dos ideais e princípios jurídicos adotados pelo Ocidente, de maneira que todos os povos reconheçam sua universalidade. Assim, a exigência de democracias, no modelo norte-americano, de Estados que garantam e respeitem eles os próprios direitos humanos já consagrados, incluindo a liberdade de religião, bem como outros tantos princípios, foi disseminada como verdadeiro "dogma", valor absoluto do qual não se pode desviar qualquer país. Ora, em síntese, tem-se uma fase "final" do constitucionalismo, que é justamente a de propagar-se e alcançar todas as nações, unificando os ideais humanos a serem consagrados juridicamente". (grifei). Em que pese a opinião do autor, atenta-se para o erro em querer padronizar o constitucionalismo ocidental como modelo a ser seguido. Tal fato constitui velada ofensa aos sistemas jurídicos do lado oriental do mapamundi. 
1) O constitucionalismo representa um marco no processo civilizatório, à medida em que surgiu para limitar o poder do monarca, para implementar a separação de funções, bem como para assegurar a previsão e, sobretudo, a concretude de direitos. Sendo assim, pode-se falar num constitucionalismo uno, cujas camadas evolutivas foram sobrepujando-se umas às outras, até o momento atual, dito neoconstitucional;

2) O fenômeno constitucionalista não está livre de equívocos, e prova disso é a necessidade de se readequar alguns excessos desse neoconstitucionalismo. Por tal razão, correntes buscam alternativas para o futuro, dentre as quais se destaca o "constitucionalismo do futuro" (ou "constitucionalismo vindouro") (ou "constitucionalismo por vir"), desenvolvido por José Roberto Dromi, e suas sete premissas fundamentais: verdade, solidariedade, consenso, continuidade, participação, integração e universalização;

3) Em que pese o respeito à posição do jurista argentino, bem como por quem o acompanha, entende-se, neste trabalho, pela desnecessidade e impossibilidade de um "constitucionalismo do futuro" no Brasil, dada a mera repetitividade, em alguns casos, de preceitos cujos institutos símiles já são aqui implementados, como é o caso da verdade, da solidariedade e do consenso; bem como a impossibilidade de aplicação de outros, como na questão de universalização.

O certo é, contudo, que o constitucionalismo segue seu prumo, e, neste diapasão, antes de pensar-se num "constitucionalismo do futuro", mister se faz readequar equívocos do neoconstitucionalismo que podem provocar, "no futuro", obstáculos incontornáveis e crises irremediáveis. A questão é, portanto, de um "constitucionalismo do presente".

BARROS, Sérgio Resende de. Contribuição dialética para o constitucionalismo. Campinas/SP: Millennium, 2007.

BARROSO, Luís Roberto. O direito constitucional e a efetividade de suas normas: limites e possibilidades da Constituição brasileira. 4. ed. Rio de Janeiro: Renovar, 2000.

BREGA FILHO, Vladimir. Direitos fundamentais na Constituição de 1988: conteúdo jurídico das expressões. São Paulo: Juarez de Oliveira, 2002. 

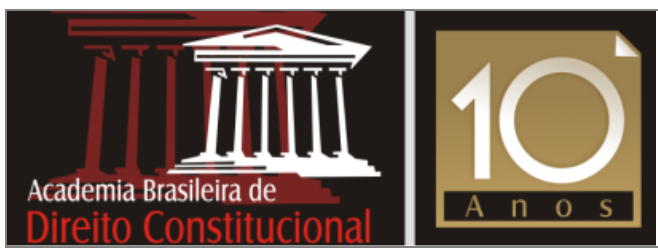

CANOTILHO, José Joaquim Gomes. Estudo sobre direitos fundamentais. Coimbra, Portugal: Coimbra Editora, 2004.

CANOTILHO, José Joaquim Gomes. Direito constitucional. 6. ed. Coimbra, Portugal: Livraria Almedina, 2002.

CIANCIARDO, Juan (coord.). La interpretacion en la era del neoconstitucionalismo. Buenos Aires, Argentina: Ábaco de Rodolfo Depalma, 2006.

DANTAS, Miguel Calmon. Constitucionalismo dirigente e pós-modernidade. São Paulo: Saraiva, 2009.

DROMI, José Roberto. La reforma constitucional: el constitucionalismo del "por venir". In: El derecho publico de finales de siglo: una perspectiva iberoamericana. Madrid: Fundación BBV, 1997.

GRASSO, Pietro Giuseppe. El problema del constitucionalismo después del Estado Moderno. Madrid, Espanha: Marcial Pons, 2005.

GRIMM, Dieter. Constitucionalismo y derechos fundamentales. Madrid, Espanha: Editorial Trotta, 2006.

KRELL, Andreas J. Direitos sociais e controle judicial no Brasil e na Alemanha: os (des)caminhos de um direito constitucional "comparado". Porto Alegre: Sergio Antonio Fabris Editor, 2002.

LOEWENSTEIN, Karl. Teoria de la Constitución. 2. ed. Barcelona: Ed. Ariel, 1970.

LUÑO, Antonio Enrique Pérez. Derechos humanos, estado de derecho y constituición. 9. ed. Madrid, Espanha: Tecnos, 2005.

OLSEN, Ana Carolina Lopes. Direitos fundamentais sociais: efetividade frente à reserva do possível. Curitiba: Juruá, 2008.

PISARELLO, Geraldo. Globalización, constitucionalismo y derechos: las vias del cosmopolitismo jurídico. In: Teoria del neoconstitucionalismo: ensayos escogidos. Madrid, Espanha: Editorial Trotta, 2007.

QUEIRÓZ, Cristina. O princípio da não-reversibilidade dos direitos fundamentais sociais. Coimbra, Portugal: Coimbra Editora, 2006.

QUEIRÓZ, Cristina. Direitos fundamentais (teoria geral). Coimbra, Portugal: Coimbra Editora, 2002. RAMOS, Elival da Silva. Ativismo judicial: parâmetros dogmáticos. São Paulo: Saraiva, 2010.

SARMENTO, Daniel. O neoconstitucionalismo no Brasil: riscos e possibilidades In: Leituras complementares de direito constitucional: teoria da Constituição. Salvador: Jus Podium, 2009.

SOARES, Mário Lúcio Quintão. Constitucionalismo e Estado. In: Constitucionalismo e Estado. Rio de Janeiro: Forense, 2006.

SOUZA JUNIOR, Cezar Saldanha. Consenso e constitucionalismo no Brasil. Porto Alegre: Sagra Luzzatto, 2002.

STRECK, Lenio Luiz. A hermenêutica jurídica nos vinte anos da Constituição do Brasil. In: O novo constitucionalismo na era pós-positivista: homenagem a Paulo Bonavides. São Paulo: Saraiva, 2009.

SUPREMO TRIBUNAL FEDERAL. Disponível em: <http://uww.stf.jus.br/arquivo/cms/noticiaArtigo Discurso/anexo/discAlemanha.pdf>. Acesso em 24 nov. 2010.

VADE MECUM RT. 5. ed. São Paulo: RT, 2010. 